\title{
Fun Handwashing and Training on Making Natural Handsanitizer
}

\author{
Eka Astutya),Elpira Asmin, and Melda Yunita
}

\author{
Program Studi Pendidikan Dokter, Fakultas Kedokteran, Universitas Pattimura, Ambon, Indonesia \\ a)Corresponding Author: ekarachman@gmail.com
}

\begin{abstract}
Regular hand washing is an important part of the WHO's COVID-19 prevention campaign and recent simulations show that much can be achieved in slowing the spread of the virus through increased hand washing. This is what underlies the community service activities located at LKSA ITTAQOLLAH as a simple step to cultivate hand washing culture while providing additional knowledge and skills to participants about making natural hand sanitizers. The preparatory stage of this activity is observing the location of the activity and managing the administration of the activity, as well as coordinating with the manager of LKSA ITTAQOLLAH. This community service activity is carried out by delivering counseling materials first. Counseling materials about the benefits of handwashing and the correct procedures for handwasing. The activity was continued with hands-on practice of handwasing, and ended with training on making natural hand sanitizers. The conclusion obtained after the implementation of this community service activity, is that the participants of the activity were very enthusiastic, the children participated in the activity from beginning to end. Increased knowledge about health in this case about how to wash hands with soap correctly and skills in this case the practice of making hand sanitizers are needed to improve the health status of children in LKSA ITTAQOLLAH.
\end{abstract}

Key words: covid 19, handwashing, handsantizer

\section{INTRODUCTION}

On March 11, 2020, the World Health Organization (WHO) confirmed the new coronavirus (COVID-19) as a pandemic amid its continued, rapid and increasing spread worldwide. WHO, together with other international and national health institutions stated, that there is currently no vaccine or drug to prevent COVID-19, the best way to reduce the spread of this virus is to reduce the tendency of exposure by washing hands and maintaining social distance. (Tartari et al. 2019)

In addition to social distancing, hand washing has been suggested repeatedly as one of the main measures to reduce transmission of the SARS-CoV-2 virus, which is responsible for the COVID-19 pandemic (Brauer et al. 2020). In a systematic review of physical interventions used to reduce transmission of respiratory viruses, hand washing was indicated to be effective with a meta-analytic summary estimate of a $45-55 \%$ reduction in transmission (Jefferson et al. 2020). Similarly, a systematic review of the effectiveness of personal protective measures in preventing transmission of pandemic H1N1 influenza in the human population showed a $38 \%$ reduction in transmission by hand washing, whereas the use of masks appears to be less effective and data for cough etiquette are insufficient (Saunders-Hastings et al. 2017). A review of influenza transmission in adults also concluded that handwashing is effective in reducing transmission (Smith et al. 2016). Handwashing with soap (CTPS) is one of the most cost-effective public health interventions (Disease Control Priorities Project 2006) and reduce the risk of diarrhea and respiratory disease by more than $20 \%$ (Aiello, Coulborn, Perez, \& Larson, 2008; Freeman et al., 2014). However, although access to hand washing facilities with soap and water is spread evenly in various places and locations in developed countries, the same is not true for developing countries. Limited access to handwashing facilities could encourage the spread of the COVID-19 pandemic so governments and aid agencies can prioritize the use of rapid access or alternatives such as alcohol-based hand sanitizer solutions to locations without such access.

Fun handwashing and training on making natural hand sanitizers as an effort to prevent the spread of the Covid-19 virus at LKSA (Child Social Welfare Institution) ITTAQOLLAH, Clove Gardens, Ambon, are a form of participation from the Faculty of Medicine, Pattimura University, 
Ambon in breaking the chain of transmission of Covid-19 in the midst of public. The selection of the location for LKSA ITTAQOLLAH is based on the results of field observations conducted by the community service team at LKSA ITTAQOLLAH, where there are 40 children who are cared for and live in this LKSA, these children are orphans and come from poor families. The results of interviews with LKSA managers obtained information that during the COVID-19 pandemic, children needed assistance in implementing clean and healthy living patterns and behaviors in order to avoid transmission of Covid-19 to children.

\section{METHOD}

Regular handwashing is an important part of the WHO's COVID-19 prevention campaign and recent simulations show that much can be achieved in slowing the spread of the virus through increased hand washing. At the same time we know that handwashing habits differ between countries and continents and the influence of cultural differences and handwashing habits on the spread of COVID-19 is not well understood. This explains why the virus is spreading faster in some countries compared to others, especially in light of recent findings that travel bans are generally ineffective in containing the spread of the virus. This is the basis for conducting community service activities located at the ITTAQOLLAH Child Welfare Institution (LKSA) as a simple step to cultivate hand washing culture while providing additional knowledge and skills to partners about making natural hand sanitizers..

The implementation of community service activities Fun handwashing and training on making natural hand sanitizers consists of several stages as follows:

\section{Preparation Stage}

The preparatory stage of this activity is observing the location of the activity and managing the administration of the activity, as well as coordinating with the manager of LKSA ITTAQOLLAH

\section{Implementation stage}

This community service activity is carried out by delivering counseling materials first. Counseling materials about the benefits of CTPS and the correct procedures for CTPS. The activity was continued with hands-on practice of CTPS, and ended with training on making natural hand sanitizers.

\section{Evaluation}

This community service activity is carried out according to a predetermined schedule. The material was presented well and used simple and easy-to-understand language considering that most of the participants in the activity were children. The interaction of the presenters and participants in the discussion and question and answer sessions which were packaged in the form of educational games also went very well.

\section{RESULTS}

This community service activity, which was held on September 12, 2021, focused on education about how to wash hands with soap and training on how to make hand sanitizer. This community service activity is carried out directly interacting with participants while still implementing health protocols. There were 40 children who participated in the activity.

The activity began with an opening and remarks by the team leader and representatives of the ITTAQOLLAH LKSA management which was then continued with the delivery of material on how to wash hands with soap (CTPS). Before delivering the material, the presenters first conducted a pre-test by asking participants to practice how to wash their hands properly. 40 children who participated in the activity, $50 \%$ of them did not know how to wash their hands properly. Errors occur in the stages of hand washing and the duration of time for washing hands and only using water without soap. 


\section{DISCUSSION}

The educational material about CTPS delivered in this activity is in the form of animated videos that are liked by children. The animated video with a short duration explains the benefits of hand washing for health, the time and activities that require hand washing and the correct hand washing steps. To create proper hand washing habits, education must be carried out from an early age. Children should be taught about the important times of hand washing (before and after eating and after using the bathroom) and the five steps of washing hands (wet, foam, rub, rinse, repeat). Most handwashing education programs begin by explaining how, why and when to wash hands. Center for Disease Control (2021) recommends washing hands by rubbing hands for at least 10-15 seconds with soap and water. All surfaces of the hands, wrists, palms, backs of hands, fingers and under nails should be washed.

Several previous studies have found that handwashing education through stories or fairy tales or posters can be an effective visual tool in helping to influence positive handwashing behavior in children. Guinan, McGuckin, \& Ali, (2002) used this intervention as part of four handwashing program activities and found a reduction in cases of infectious diseases in children. These activities include presentations and discussions combined with educational videos, handouts for children to color, and ensuring that resources such as soap, hand wipes, and hand sanitizers are available for children to wash their hands..

The practice of making hand sanitizer made from natural ingredients is also carried out as part of this community service activity. Although washing your hands with soap and water is the best way to get rid of germs in most situations. However, if soap and water are not available, we can use an alcohol-based hand sanitizer that contains at least $60 \%$ alcohol (Center for Disease Control, 2021a).

\section{CONCLUSIONS AND RECOMMENDATIONS}

The conclusion obtained after the implementation of this community service activity, is that the participants of the activity were very enthusiastic, the children participated in the activity from beginning to end in an orderly manner. Increased knowledge about health in this case about how to wash hands with soap correctly and skills in this case the practice of making hand sanitizers are needed to improve the health status of children in LKSA ITTAQOLLAH.

Hand washing is the most important measure to prevent the spread of disease and maintain one's health. Hand washing reduces the risk of antibiotic resistance or the risk of developing disease so that children and young people become important targets for the adoption of hand washing habits. Hand sanitizer is very helpful when soap and water are not available in the environment, but cannot completely replace hand washing

\section{ACKNOWLEDGMENTS}

We express our gratitude to Allah Subhanahu Wa Ta'ala, because for the facilities provided so that this Community Service can run smoothly. Thank you and appreciation to the Faculty of Medicine, University of Pattimura who has supported the funding of this community service activity.

\section{REFERENCES}

Aiello, Allison E., Rebecca M. Coulborn, Vanessa Perez, and Elaine L. Larson. 2008. "Effect of Hand Hygiene on Infectious Disease Risk in the Community Setting: A Meta-Analysis." American Journal of Public Health 98(8):1372-81.

Brauer, Michael, Jeff T. Zhao, Fiona B. Bennitt, and Jeffrey D. Stanaway. 2020. "Global Access to Handwashing: Implications for COVID-19 Control in Low-Income Countries." MedRxiv 16.

Disease Control Priorities Project. 2006. Disease Control Priorities in Developing Countries, 2nd Edition. 2nd ed. edited by D. T. Jamison, J. G. Breman, A. R. Measham, G. Alleyne, M. Claeson, D. B. Evans, P. Jha, A. Mills, and P. Musgrove. Washington DC: Oxford University Press.

Freeman, Matthew C., Meredith E. Stocks, Oliver Cumming, Aurelie Jeandron, Julian P. T. 
Higgins, Jennyfer Wolf, Annette Prüss-Ustün, Sophie Bonjour, Paul R. Hunter, Lorna Fewtrell, and Valerie Curtis. 2014. "Systematic Review: Hygiene and Health: Systematic Review of Handwashing Practices Worldwide and Update of Health Effects." Tropical Medicine and International Health 19(8):906-16.

Jefferson, Tom, Chris B. Del Mar, Liz Dooley, Eliana Ferroni, Lubna A. Al-Ansary, Ghada A. Bawazeer, Mieke L. van Driel, Mark A. Jones, Sarah Thorning, Elaine M. Beller, Justin Clark, Tammy C. Hoffmann, Paul P. Glasziou, and John M. Conly. 2020. "Physical Interventions to Interrupt or Reduce the Spread of Respiratory Viruses." The Cochrane Database of Systematic Reviews 11:CD006207.

Saunders-Hastings, Patrick, James A. G. Crispo, Lindsey Sikora, and Daniel Krewski. 2017. "Effectiveness of Personal Protective Measures in Reducing Pandemic Influenza Transmission: A Systematic Review and Meta-Analysis." Epidemics 20:1-20.

Smith, Sheree M. .., Sandra Sonego, Gwenyth R. Wallen, Grant Waterer, Allen C. Cheng, and Philip Thompson. 2016. "Use of Non-Pharmaceutical Interventions to Reduce the Transmission of Influenza in Adults: A Systematic Review Sheree." Respirology 20(6):896903.

Tartari, Ermira, Carolina Fankhauser, Alexandra Peters, Buyiswa Lizzie Sithole, Funda Timurkaynak, Sarah Masson-Roy, Benedetta Allegranzi, Daniela Pires, and Didier Pittet. 2019. "Scenario-Based Simulation Training for the WHO Hand Hygiene Self-Assessment Framework." Antimicrobial Resistance and Infection Control 8(1):4-9. 


\section{APPENDIX}
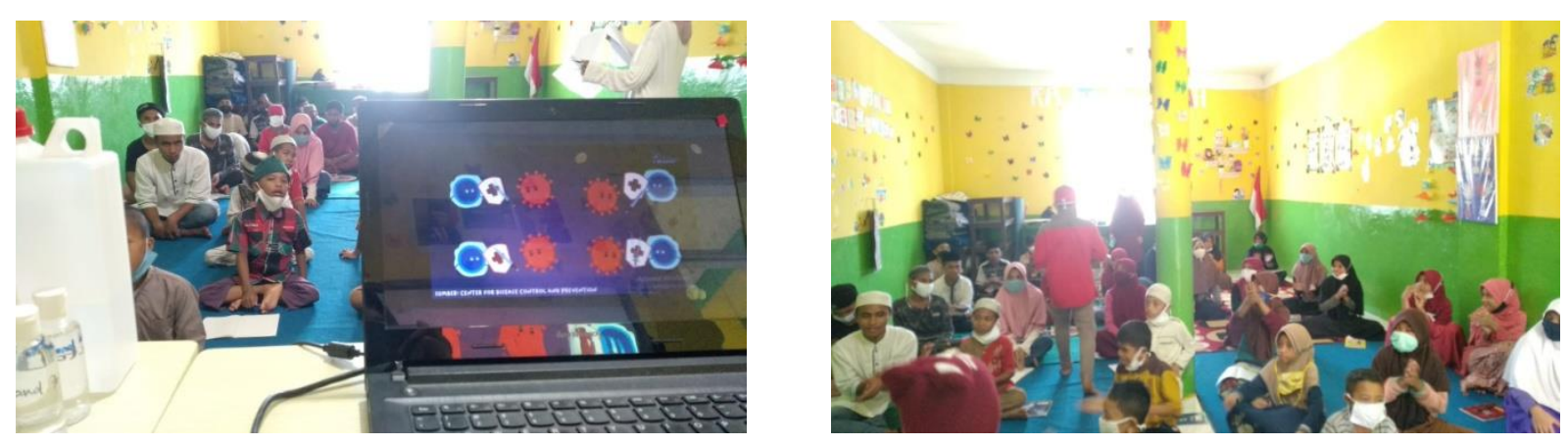

Figure 1. Submission of hand washing materials with soap

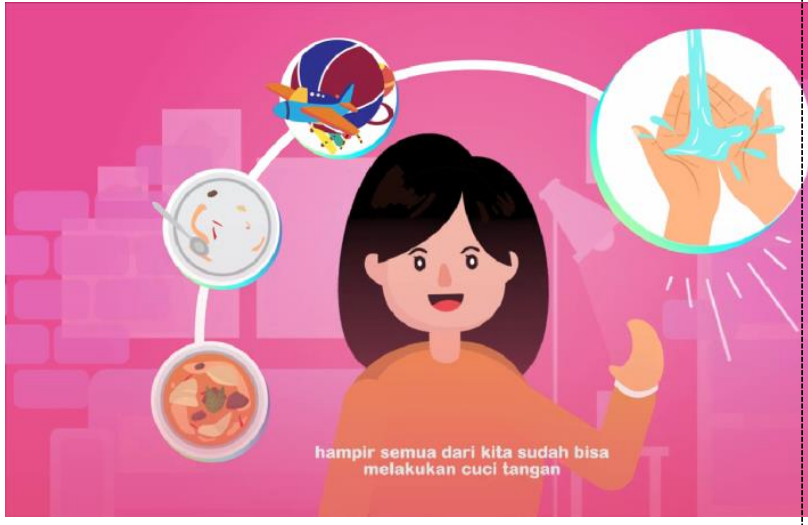

Figure 2. Screenshot of the animated video display in delivering CTPS material

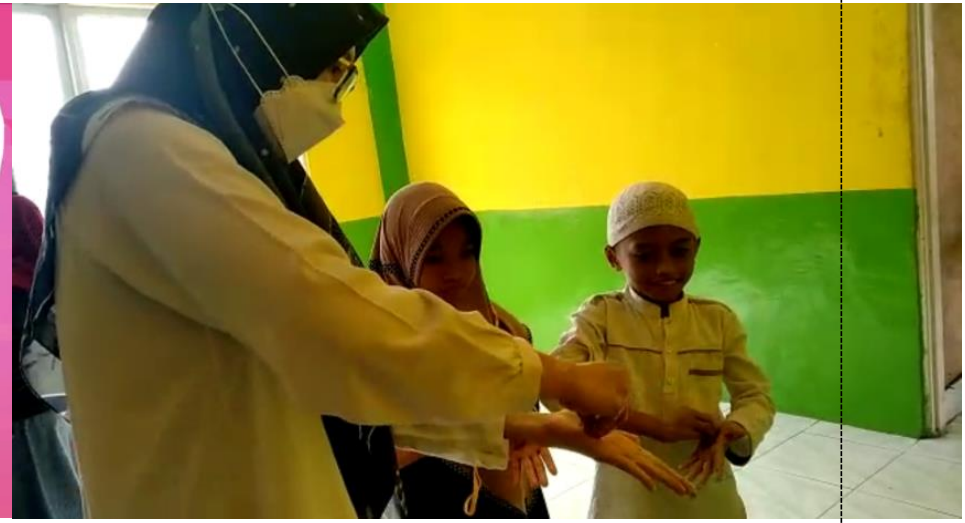

Figure 3. The direct practice of washing hands with soap by activity participants is guided by one of the activity team members
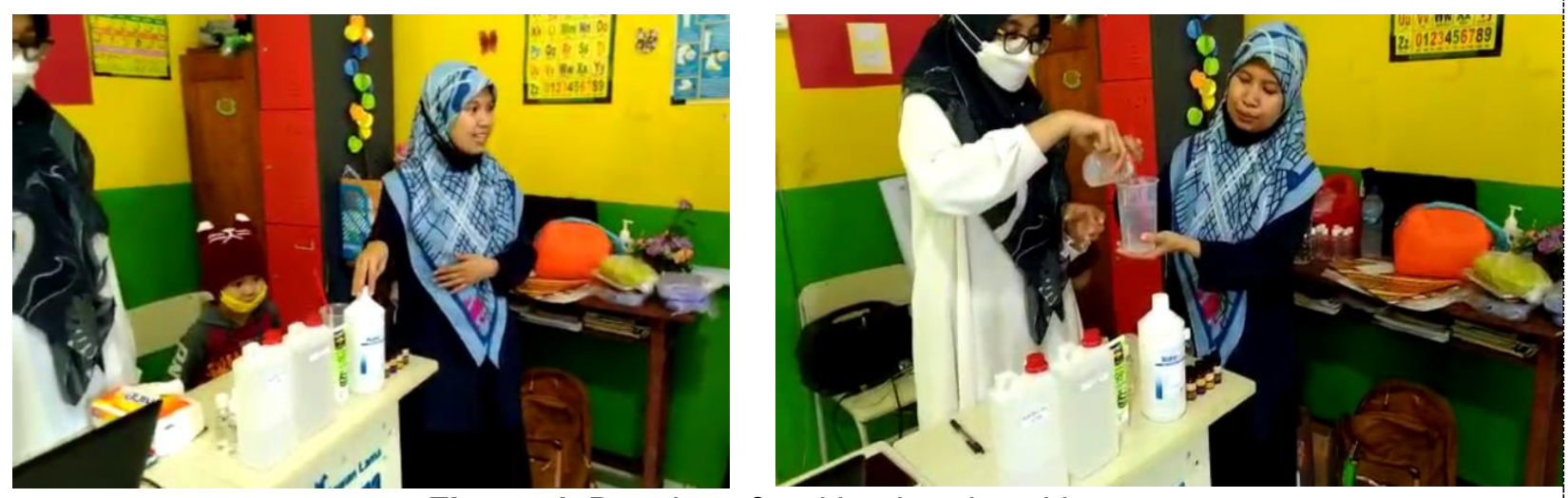

Figure 4. Practice of making hand sanitizer 